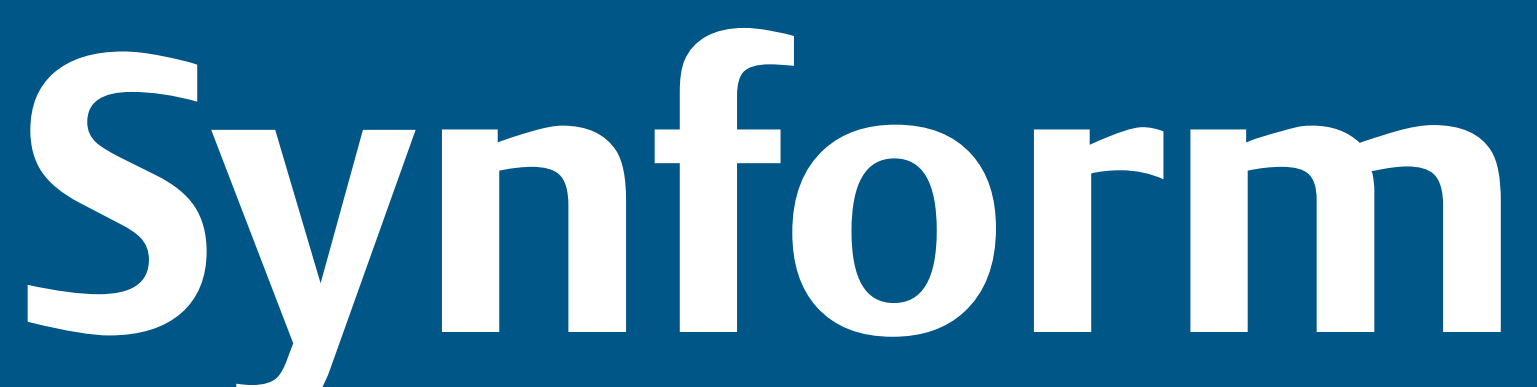

People, Trends and Views in Chemical Synthesis

$$
2021 / 07
$$

\title{
Asymmetric Three-Component Olefin Dicarbofunctionalization Enabled by Photoredox and Copper Dual Catalysis
}

Highlighted article by P.-Z. Wang, Y. Gao, J. Chen, X.-D. Huan, W.-J. Xiao, J.-R. Chen

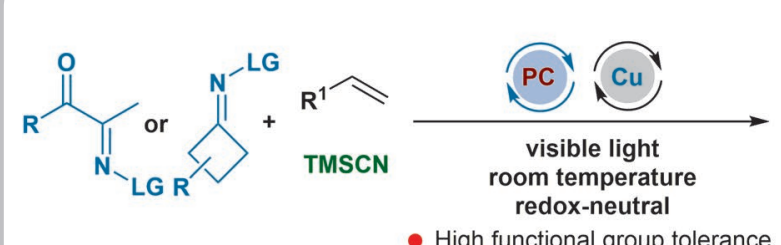

- High functional group tolerance

- Broad scope of C-radical precursors

- Excellent chemo- and enantioselectivity

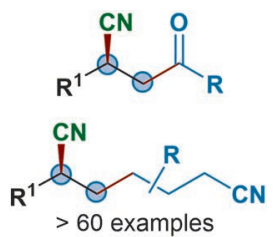
up to $86 \%$ yield up to $97 \%$ ee

\section{Contact}

Your opinion about Synform is welcome, please correspond if you like:

marketing@thieme-chemistry.com
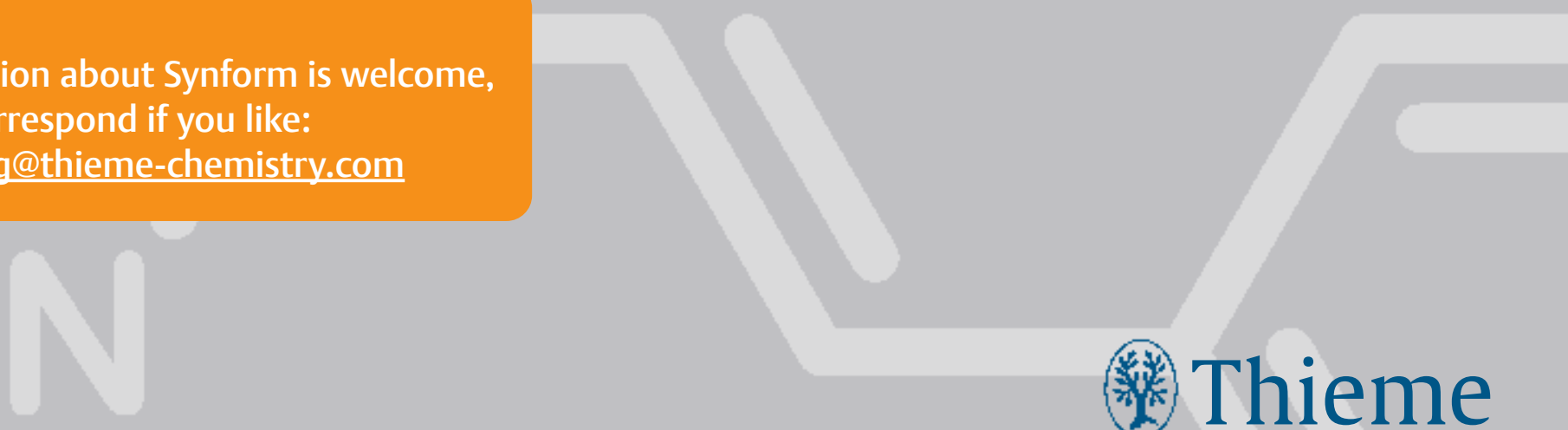


\section{Dear Readers,}

I am delighted to introduce a very rich July issue of SYNFORM, with five articles instead of the usual four. In the opening extra article, we are incredibly pleased to welcome Professor Martin Oestreich (Technische Universität Berlin, Germany), who joined the Editorial Board of SYNTHESIS with effect from April 1, 2021. Martin is a fantastic addition to the Thieme Chemistry editorial boards team and in this introductory interview we have the opportunity to get to know him - and his research - a bit better. The issue continues with another interview, a Young Career Focus article with Quentin Michaudel (USA), who speaks with SYNFORM about his research interests at the interface of organic synthesis and polymer science. The first literature coverage article of the issue concerns a highly innovative and original strategy for forming peptide bonds by exploiting the potential of visible light, designed and developed by Y. Eichen and A. M. Szpilman (Israel). The next article covers a novel exciting methodology developed by W.-J. Xiao and J.-R. Chen (P.R. of China) for functionalizing both ends of an olefin with TMSCN and an oxime ester, exploiting once again the potential of visible light, in this case combined with copper catalysis. The issue is closed by a very exciting metal-free method for incorporating two different functions - an azide and a trifluoromethyl group - across a double bond, relying on the power of radical chemistry, as originally reported in a Science paper by W.-B. Liu (P.R. of China).

Enjoy your reading!!

\section{In this issue}

Editorial Board Focus

Editorial Board Focus: Professor Martin Oestreich (Technische Universität Berlin, Germany)

Young Career Focus

Young Career Focus: Prof. Quentin Michaudel

(Texas A\&M University, USA)

- Literature Coverage

Solar and Visible Light Assisted Peptide Synthesis ... A112

- Literature Coverage

Asymmetric Three-Component Olefin Dicarbofunctionalization Enabled by Photoredox and Copper Dual

Catalysis

Literature Coverage

Trifluoromethanesulfonyl Azide as a Bifunctional Reagent for Metal-Free Azidotrifluoromethylation of Unactivated Alkenes

Coming soon

\section{Contact}

If you have any questions or wish to send feedback, please write to Matteo Zanda at: synform@outlook.com

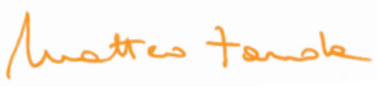




\title{
Editorial Board Focus: Professor Martin Oestreich (Technische Universität Berlin, Germany)
}

\author{
Background and Purpose. SYNFORM portraits Thieme Chemistry Editorial Board or Editorial Advisory Board \\ members who answer several questions regarding their research interests and revealing their impressions \\ and views on the developments in organic chemistry as a general research field. This Editorial Board Focus \\ presents Professor Martin Oestreich (Technische Universität Berlin, Germany) who joined the Editorial Board \\ of SYNTHESIS with effect of April 1, 2021.
}

\section{Biographical Sketch}

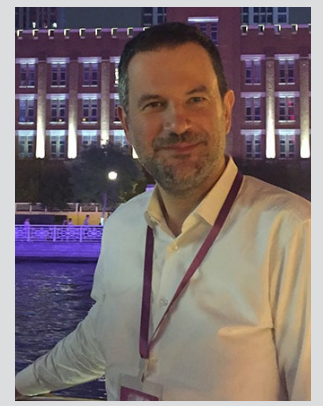

Prof. M. Oestreich
Martin Oestreich is Professor of Organic Chemistry at the Technische Universität Berlin; his appointment was supported by the Einstein Foundation Berlin. He received his diploma degree with Paul Knochel (Marburg, Germany, 1996) and his doctoral degree with Dieter Hoppe (Münster, Germany, 1999). After a two-year postdoctoral stint with Larry E. Overman (Irvine, USA, 1999-2001), he completed his habilitation with Reinhard Brückner (Freiburg, Germany, 2001-2005) and was appointed as Professor of Organic Chemistry at the Westfälische Wilhelms-Universität Münster (2006-2011). He also held visiting positions at Cardiff University in Wales (UK, 2005), at The Australian National University in Canberra (Australia, 2010), and at Kyoto University in Japan (2018). Martin's research mainly focuses on silicon in synthesis and catalysis. His early work centered around the use of silicon-stereogenic silicon reagents in asymmetric catalysis, and his laboratory continues to employ them as stereochemical probes in mechanistic investigations. His research group made fundamental contributions to catalytic carbon-silicon bond formation with nucleophilic and, likewise, electrophilic silicon reagents, and Martin is probably best known for his work in silylium-ion chemistry. Recent accomplishments of his laboratory include the synthesis of the "fat proton" $\mathrm{H}_{3} \mathrm{Si}^{+}$ and the dynamic kinetic resolution of alcohols by enantioselective silylation. Martin recently edited a monograph entitled Organosilicon Chemistry: Novel Approaches and Reactions together with Tamejiro Hiyama.

\section{INTERVIEW}

SYNFORM Please comment on your role as a member of the Editorial Board of SYNTHESIS with a focus on your specific role.

Prof. M. Oestreich SYNTHESIS stepped into my life when I joined the group of Professor Dieter Hoppe nearly 25 years ago. I have been a follower of the journal ever since, and it is an honor for me to indirectly and directly succeed my former mentors Dieter Hoppe and Paul Knochel, respectively. As an editor of SYNTHESIS handling review articles, my goal is to maintain and further strengthen the journal's high visibility and top-level quality. These are times of changes in the publishing business, with new journals - and, as such, competitors - appearing regularly, but winning papers from the leaders and rising stars of their fields for SYNTHESIS is a challenge I am more than happy to accept.

SYNFORM How do you describe the value of a product such as SYNTHESIS to the chemistry community?

Prof. M. Oestreich Review articles have always been central to the journal's content and continue to be an important reference for the chemistry community. This is why I believe that SYNTHESIS belongs to the relevant journals in the area of synthetic chemistry. It offers a great package with comprehensive reviews, timely short reviews, and original contributions.

SYNFORM What is the focus of your current research activities?

Prof. M. Oestreich We are broadly interested in chemistry involving the main-group element silicon. I find it difficult to single out certain research activities, but our recently introduced ionic transfer processes driven by aromatization have 
given us a lot of joy. It began with transfer hydrosilylation and developed into a general strategy for hydrofunctionalization of carbon-carbon multiple bonds using stable cyclohexadiene-based surrogates.

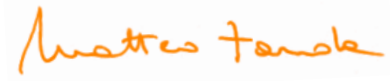




\section{Young Career Focus: Prof. Quentin Michaudel (Texas A\&M University, USA)}

Background and Purpose. SYNFORM regularly meets young up-and-coming researchers who are performing exceptionally well in the arena of organic chemistry and related fields of research, in order to introduce them to the readership. This Young Career Focus presents Prof. Quentin Michaudel (Texas A\&M University, USA).

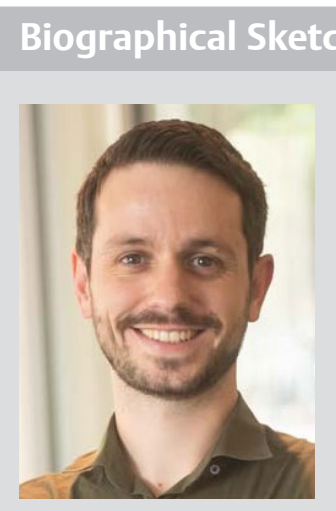

Prof. Q. Michaudel
Quentin Michaudel received his B.Sc. (2008) and M.Sc. (2010) from the École Normale Supérieure de Lyon (France). He then earned his Ph.D. (2015) under the guidance of Professor Phil S. Baran at The Scripps Research Institute (USA), where he explored $\mathrm{C}-\mathrm{H}$ functionalization methods and their applications to the synthesis of complex molecules. Upon graduation, Quentin began a postdoctoral appointment at Cornell University (USA), working with Professor Brett P. Fors on the development of photocontrolled polymerizations and the design of biorenewable monomers. In 2018, Quentin started his independent career as an assistant professor at Texas A\&M University (USA) in the Department of Chemistry and, as of 2019, is also affiliated with the Department of Materials Science and Engineering. His research focuses on the development of synthetic methods to access polymers with unique architectures and properties, as well as bioactive molecules and $\pi$-conjugated materials. Olefin metathesis, click reactions, benzyne chemistry, and photochemical transformations are but a few reaction manifolds currently explored in his group. He was the recipient of the Thieme Chemistry Journals Award in 2021.

\section{INTERVIEW}

SYNFORM What is the focus of your current research activity?

Prof. Q. Michaudel Currently, my group's interests center on the implementation of modern organic reactions to synthesize unprecedented polymeric architectures, as well as complex molecules in general. For example, we are designing reactions for the selective functionalization of bioactive molecules and the synthesis of polymers via Sulfur(VI) Fluoride Exchange (SuFEx) click chemistry. Of particular interest is the exploration of the chemistry of sulfamides and polysulfamides with an emphasis on harnessing their hydrogen-bond behaviors for a variety of applications. Another focus is the study of polymerization processes based on stereoretentive olefin metathesis as a means to access new conjugated polymers with an eye toward the production of materials for energy storage and production (e.g., batteries, photovoltaic devices). Finally, we are interested in the invention of green chemical transformations via photocatalysis or electrochemistry, and the development of sustainable polymers that can be depolymerized after use.

\section{SYNFORM When did you get interested in synthesis?}

Prof. Q. Michaudel I became interested in chemistry at an early age, but my love for synthesis really started as a student at the École Normale Supérieure de Lyon (France). During my master's studies, I had the opportunity to spend six months in the laboratory of Prof Phil Baran at The Scripps Research Institute (USA) as a visiting student, which cemented my desire to pursue a career in organic synthesis. During this internship, I was tasked with the development of a stereoselective synthesis of the active metabolite of the antiplatelet medication clopidogrel (Plavix ${ }^{\mathrm{TM}}$ ), which is one of the most commonly prescribed drugs in the world. The exact stereochemistry of this unstable metabolite was unknown at the 
time. This project was a collaborative effort with the pharmaceutical Bristol-Myers Squibb and together, we were able to develop three complementary routes to the different metabolites of clopidogrel. ${ }^{1}$ This experience was transformative in many ways. It was the longest synthetic sequence I had ever worked on (13 linear steps) and I had to learn how to work with minute amounts of compounds to optimize each step. More importantly, my knowledge of organic synthesis drastically improved through the discussions with my advisor, the guidance of the postdoctoral researcher mentoring me, and the intellectually stimulating atmosphere of the Baran laboratory. It was also the first time that my academic interest for synthesis coincided with solving a "real life" problem. Following my PhD at Scripps, I joined the group of Prof. Brett Fors at Cornell University (USA) to expand my chemistry horizons. There, I utilized my synthetic expertise and my knowledge of radical mechanisms to design new polymerization processes with the help of talented co-workers. My training in both organic chemistry and polymer synthesis provides me with a unique opportunity to lead an independent research group at the interface of both fields.

SYNFORM What do you think about the modern role and prospects of organic synthesis?

Prof. Q. Michaudel Organic synthesis is a very mature field of research and discovering new modes of reactivity has become increasingly challenging. However, the potential of organic synthesis to unlock disruptive technologies and world-changing inventions has never been as apparent, nor as exciting. From modern medicine to agrochemicals; plastic packaging to tires and coatings; and solar cells to $\mathrm{CO}_{2}$ capture, organic synthesis has delivered - and will continue to provide - the molecules and materials that sustain and improve our way of life. With the modern arsenal of organic reactions, the practitioner is limited only by their imagination in designing new molecules with unique functions and behaviors. This wealth of methods will continue to drive discoveries, not only in chemistry, but also in adjacent fields such as biology, physics, materials science, and beyond.

SYNFORM Could you tell us more about your group's areas of research and your aims?

Prof. Q. Michaudel As previously mentioned, my group works at the interface of organic chemistry and polymer science. Broadly speaking, we are trying to push the boundaries of polymer synthesis via the design of new monomers and the invention of unique methods of polymerization. Once we have produced new polymeric materials, we study their physical properties for potential applications. These investigations include the typical analyses of thermal and mechanical properties, as well as state-of-the-art spectroscopy techniques to unveil the electronic and optical properties of our conjugated materials. Our foray into uncharted polymer space relies first and foremost on the synthesis of many small molecules as monomers, catalysts, or as model substrates to probe chemical reactivity.

SYNFORM What is your most important scientific achievement to date and why?

Prof. Q. Michaudel Convincing a diverse group of talented young scientists to help me launch a new lab and witnessing their scientific growth is certainly the achievement I am most proud of. While we still have a lot of work ahead of us, we have already reached some key milestones. Last year, we reported that the stereoretentive ring-opening metathesis polymerization (ROMP) of a paracyclophane diene monomer enables the preparation of all-cis poly(phenylene vinylene)s with perfect stereoselectivity and exquisite control over the polymer chain growth (Scheme 1). ${ }^{2}$ This unique approach enabled the synthesis of photoresponsive diblock copolymers via isomerization of the olefins in the polymer backbone triggered with UV-light. As demonstrated in this study, the level of control afforded by stereoretentive dithiolate Ru-catalysts first prepared by Hoveyda and co-workers ${ }^{3}$ provides an additional knob for polymer chemists to tune the properties of their materials. ${ }^{4}$ In a second communication, ${ }^{5}$ we described a mild and efficient synthesis of unsymmetrical sulfamides via the SuFEx click reaction pioneered by Sharpless and co-workers. ${ }^{6}$ The optimized conditions delivered a variety of sulfamides from primary and secondary amines in excellent yields (Scheme 2a). Capitalizing on this robust process, we synthesized a

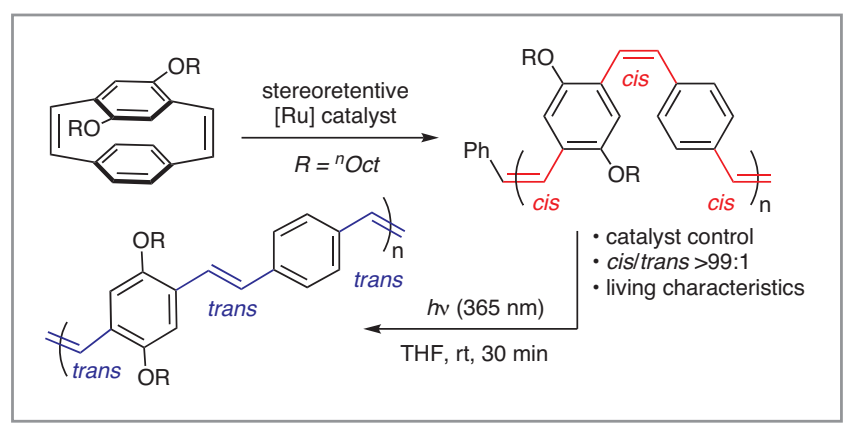

Scheme 1 Synthesis of all-cis PPV via stereoretentive ROMP and photoisomerization to the all-trans congener. 


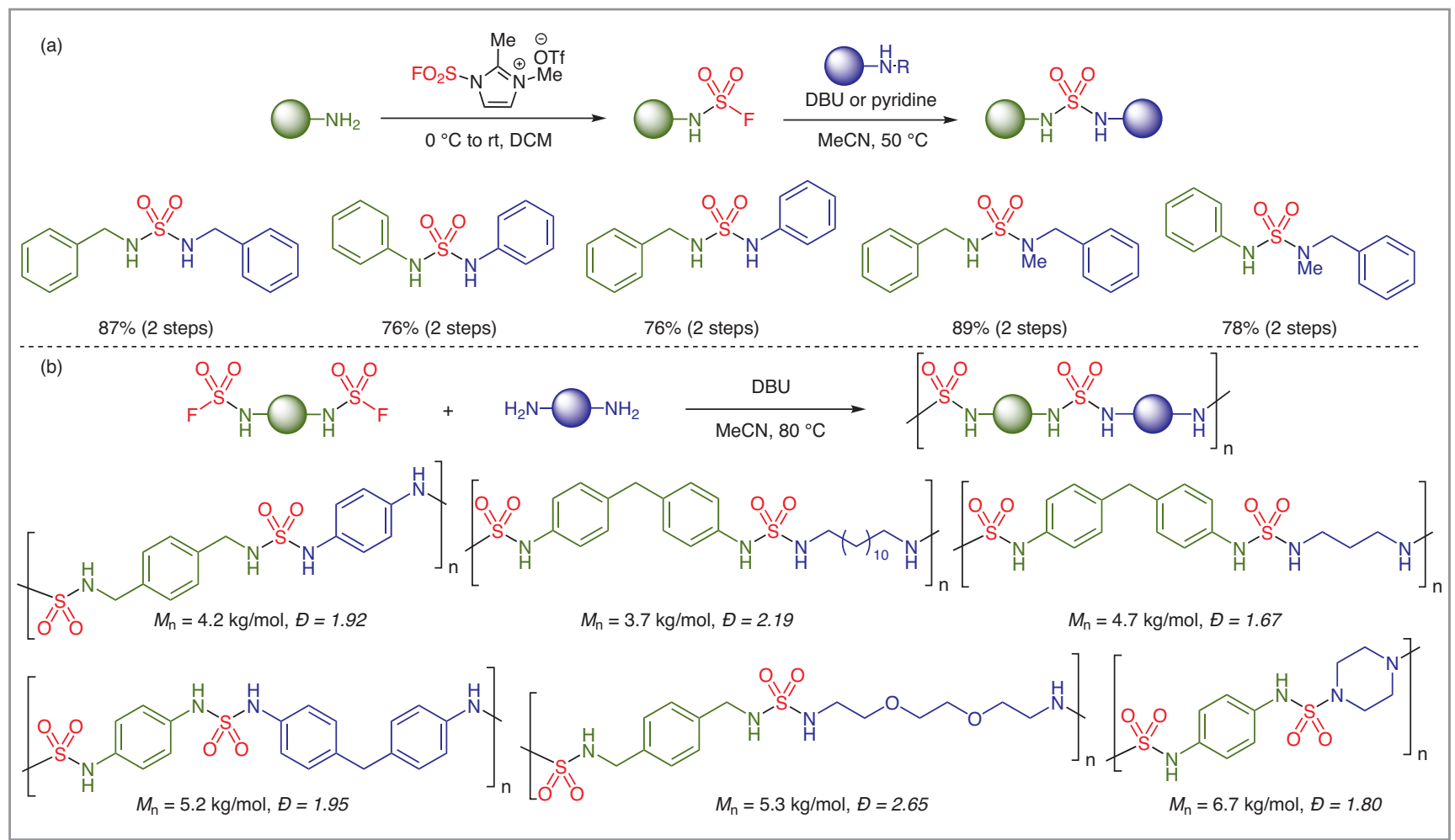

Scheme 2 Synthesis of sulfamides via SuFEx click chemistry. (a) Reaction development. (b) Application to the synthesis of polysulfamides (selected examples). $M_{\mathrm{n}}=$ Number-average molecular weight; $€$ = dispersities.

library of polysulfamides (Scheme 2b), an underexplored family of macromolecules whose properties are tied to their propensity to engage in hydrogen bonding. Aryl polysulfamides were shown to decompose back to the starting bisamine monomer under acid or basic hydrolysis, paving the way for potential polymer recycling. We hope that this new method will facilitate the adoption of sulfamides as bioisosteres, as catalysts, and, more generally, as linchpins for the synthesis of complex molecules, including macromolecules.

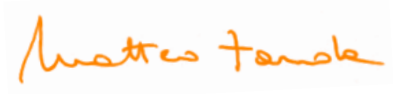

\section{REFERENCES}

(1) S. A. Shaw, B. Balasubramanian, S. Bonacorsi, J. Caceres Cortes, K. Cao, B.-C. Chen, J. Dai, C. Decicco, A. Goswami, Z. Guo, R. Hanson, W. G. Humphreys, P. Y. S. Lam, W. Li, A. Mathur, B. D. Maxwell, Q. Michaudel, L. Peng, A. Pudzianowski, F. Qiu, S. Su, D. Sun, A. A. Tymiak, B. P. Vokits, B. Wang, R. Wexler, D.-R. Wu, Y. Zhang, R. Zhao, P. S. Baran J. Org. Chem. 2015, 80, 7019-7032.

(2) T.-W. Hsu, C. Kim, Q. Michaudel J. Am. Chem. Soc. 2020, 142, 11983-11987.

(3) R. K. M. Khan, S. Torker, A. H. Hoveyda J. Am. Chem. Soc. 2013, 135, 10258-10261.

(4) S. J. Kempel, T.-W. Hsu, Q. Michaudel Synlett 2021, 32, 851-857.

(5) R. W. Kulow, J. W. Wu, C. Kim, Q. Michaudel Chem. Sci. 2020, 11, 7807-7812.

(6) J. Dong, L. Krasnova, M. G. Finn, K. B. Sharpless Angew. Chem. Int. Ed. 2014, 53, 9430-9448. 


\title{
Solar and Visible Light Assisted Peptide Synthesis
}

\author{
Angew. Chem. Int. Ed. 2021, 60, 12406-12412
}

With the growth in the use of peptides in modern medicine and materials, ${ }^{1}$ the development of novel amide- and peptidebond-forming reactions have been deemed amongst the most important goals for modern organic synthesis. ${ }^{2}$ Current peptide coupling methods are extremely powerful and selective, but rely heavily on water-sensitive, high-molecular-weight coupling agents that are often prepared in multiple steps and can lead to large amounts of unwanted co-products.

Transition-metal-catalyzed visible-light photocatalysis has been a mainstay in state-of-the-art synthetic chemistry in the last decade and a half. ${ }^{3}$ In many of these reactions, an amine is oxidized to give an imine which may undergo further transformations. ${ }^{4}$ This oxidation takes place via a nitrogen radical cation intermediate.

The groups of Professor Alex Szpilman at Ariel University (Ariel, Israel) and Professor Yoav Eichen at the Technion - Israel Institute of Technology (Haifa, Israel) have been interested in visible-light-assisted synthetic chemistry for some time. Professor Szpilman explained: "We started with the pioneering work by e.g. Lautenberger that showed that visible light may activate amine-halo-alkane charge-transfer complexes, resulting in the formation of halogen radicals, nitrogen radical cations, and ultimately imines. ${ }^{5}$ Our initial excursion into the use of this principle led to the development of a visiblelight-assisted amide bond formation between tri-substituted amines and carboxylic acids. ${ }^{6}$ However, in this process one of the three alkyl substituents of the amine was unavoidably lost, via imine formation, as part of the required formal dehydration condensation. The reaction was also very slow. This work was carried out by Dr. Irit Cohen, a former joint Ph.D. student, together with two of the co-authors of this paper, Galit Parvari and Abhaya K. Mishra."

Professor Szpilman recalls that during this previous research campaign, ${ }^{6}$ a second key component that would eventually lead to the present work was the shift from using blue LED as a convenient light source to using the sun instead. "In the course of a discussion on this project, we basically looked out of the window and realized the folly of limiting our work to artificial light sources," said Professor Szpilman. One of the key advantages of using sunlight is that it is freely available. Its intensity may be easily measured in a given location and may even be predicted for any given day and area. "While some parts of the world have less intense light or short winter days this may be compensated for by choosing the right time of day or substituting a powerful white LED that generates light in the 330-450 $\mathrm{nm}$ region where the 4-dimethylaminopyridine (DMAP)- $\mathrm{Br}-\mathrm{CCl}_{3}$ complex absorbs," explained Professor Szpilman. He continued: "Importantly, the energy-rich shorter-UV components of sunlight that could lead to decomposition of the reactants or byproducts could be filtered off simply by using a standard Pyrex glass vessel that has a cutoff around 330 nm."

Despite these attractive features, it was painfully obvious to the researchers that the original process could not be applied to peptide synthesis. Loss of one alkyl substituent from the amine reactant and the long reaction times that might cause epimerization were the main challenges that needed to be overcome. Furthermore, only trialkylamine and dialkylamine charge-transfer complexes with tetrachloromethane absorbed in the near UV-VIS part of the electromagnetic spectrum at synthetically relevant concentrations. "Thus, we arrived at the idea of using DMAP as both the amine responsible for forming the charge-transfer complex that would absorb in the desirable part of the spectrum, and as the precursor for the peptide coupling reagent (Scheme 2)," explained Professor Szpilman.

"The fact that DMAP is a low-molecular-weight and inexpensive amine were important considerations," remarked Professor Szpilman. He continued: "Furthermore, the fact that DMAP is always included as an acylation catalyst in most peptide coupling methods meant that the number of reagents in our proposed method would actually be reduced compared to standard methods. Indeed, DMAP formed charge-transfer complexes with tetrachloromethane, that when irradiated with sunlight allowed coupling of standard $N$-protected amino acids with methyl and ethyl esters of a second amino acid. However, the reaction was still rather slow. Furthermore, tetrachloromethane was used as a co-solvent in order to compensate for the equilibrium for the charge-transfer complex formation being heavily shifted towards the un-complexed reactants. By substituting bromotrichloromethane for tetrachloromethane, it was possible to reduce the amount of both DMAP and alkyl halide to 10 equivalents and the peptide coupling reactions could now be carried out typically in an hour or less using sunlight. Two equivalents of the amino acid serving as the free amine component were required for optimal yield, but the low cost of amino acid methyl and ethyl ester hydrochlorides, especially when aiming at longer-chain peptides, reduced the significance of this issue. Excess of one 
of the peptide-coupling partners is also common in other methods."

Professor Szpilman advised that the reaction is run best at around $30{ }^{\circ} \mathrm{C}$. The internal temperature at the end of one hour sunlight irradiation was typically $32{ }^{\circ} \mathrm{C}$, but it was found that when the reaction was run on colder days where the internal temperature reached only $20^{\circ}$ the reaction was slower and the yields lower. Therefore, the authors recommend using a water bath if the reaction is run using sunlight in cold weather or in the lab using a LED lamp.

Under such conditions, the reaction is compatible with all the standard protecting groups (Scheme 1 and Figure 1) and all standard amino acids with the exception of methionine.
Professor Szpilman said: "An additional advantage of the weakly absorbing DMAP- $\mathrm{BrCCl}_{3}$ charge-transfer complex is that it can be scaled up to gram scale (Figure 1) without the need for flow systems that are typically necessary for strongly absorbing transition-metal-catalyzed visible light mediated reactions. On gram-scale, excess DMAP is easily recovered during chromatography."

"To support our mechanistic hypothesis, we carefully studied the intermediates formed and were lucky to be able to isolate the DMAP-imine adduct shown in Scheme 2," said Professor Szpilman. He continued: "The proposal was further supported by computational studies on the charge-transfercomplex formation, including the barrier for formation as well

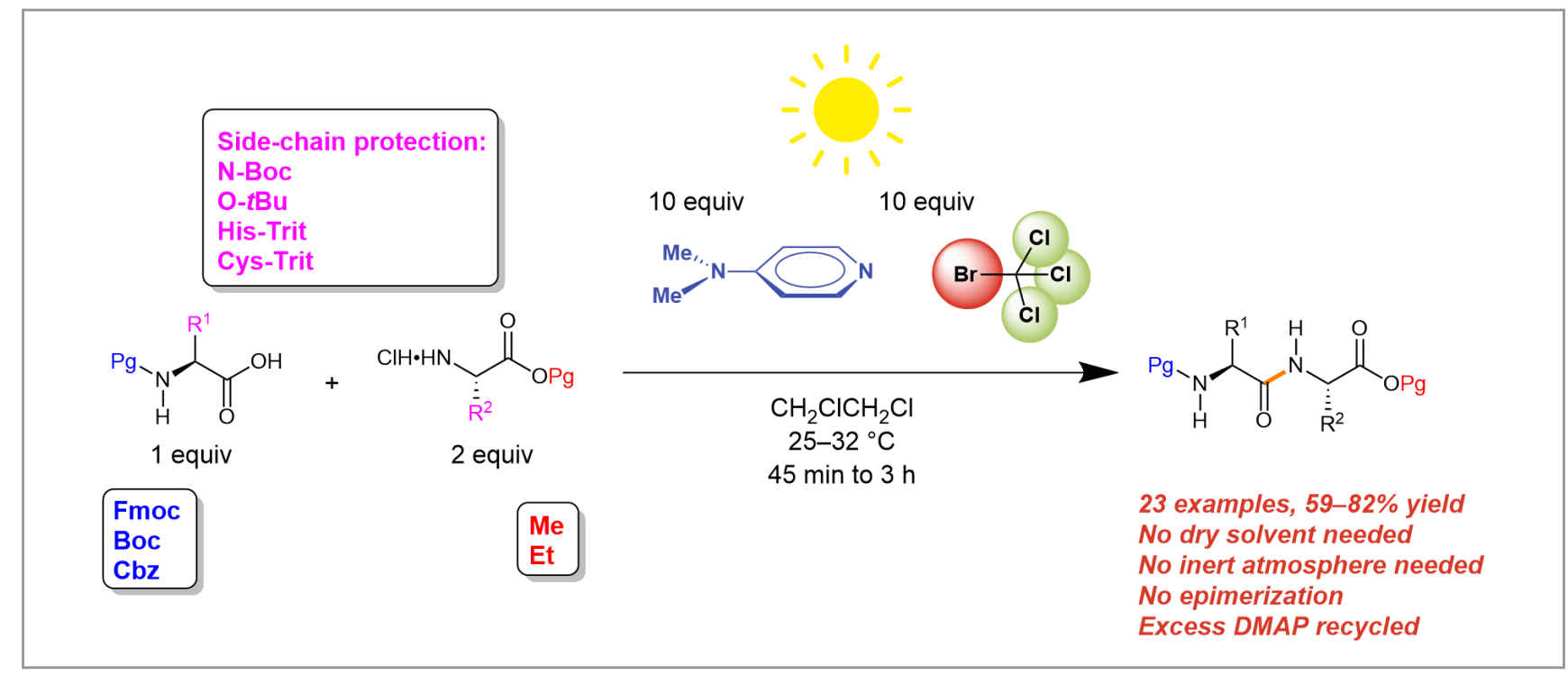

Scheme 1 Overview of the sunlight-assisted peptide coupling reaction<smiles>CCOC(=O)CNC(=O)C(Cc1ccccc1)NC(=O)C(NC(F)F)[C@H](C)CC</smiles>

Fmoc-L-lle-L-Phe-Gly-OEt

1. Peptide Coupling, 60 min, $83 \%$ $1.2 \mathrm{~g}$ scale

2. $\mathrm{LiOH}, 40 \mathrm{~min}, 84 \%$

3. Peptide Coupling, 60 min, $74 \%$<smiles>COC(=O)[C@H](CC(C)C)NC(=O)C(Cc1ccccc1)NC(=O)CNC(=O)OC(C)(C)C</smiles>

Boc-Gly-L-Phe-L-Leu-OMe

1. Peptide Coupling, 50 min, $92 \%$

2. $\mathrm{LiOH}, 40 \mathrm{~min}, 84 \%$

3. Peptide Coupling, $60 \mathrm{~min}, 86 \%$<smiles>COC(=O)[C@H](C)NC(=O)[C@H](CC(C)C)NC(=O)C(COCc1ccccc1)NC(=O)OC(C)(C)C</smiles>

Boc-L-Ser(Bzl)-L-Leu-L-Ala-OMe

1. Peptide Coupling, 50 min, $91 \%$

2. $\mathrm{LiOH}, 40 \mathrm{~min}, 83 \%$

3. Peptide Coupling, $60 \mathrm{~min}, 89 \%$

Figure 1 Selected examples 
as its lowest-energy triplet state. The two calculation levels of theory chosen for this study were MP4SDTQ/6-31G(2df,p) and m062x/6-31G(2df,p) with an SMD continuum solvation model. The MP4 functional ${ }^{8}$ was selected due to findings on a similar system (phosphorus-bromine bonding) and was shown to be considerably superior over MP2. ${ }^{9}$ The $\mathrm{m} 062 \mathrm{x}$ functional ${ }^{10}$ was shown ${ }^{11}$ to be among the best available hybrid functionals for calculating halogen-bound systems. Our addition of the solvation model was due to non-negligible interaction between the components, persisting even over large distances (120 ̊). These calculations allowed us to establish the structural geometries for the complexes and allowed us to propose that the reaction proceeds through formation of a DMAP-Br radical cation and a trichloromethane radical as intermediates which are subsequently converted into the observed DMAP-imine cation and chloroform, as shown in Scheme 2."

Professor Szpilman said: "Future developments and applications include developing better charge-transfer-complex partners for DMAP that may allow for reduction of the amounts of these components, as well possibly the amount of the amine-coupling partner. Application of the method to larger scale, namely kilo- or ton-scale peptide coupling, will likely require use of flow chemistry technology $\mathrm{y}^{12}$ as well as the development of product recovery techniques that do not require chromatographic separation and purification of the products. Nonetheless, the use of an endergonic charge-transfer complex as the photoactive intermediate implies that the absorbing species is always at a low but constant concentration, allowing for deep light penetration to the reacting medium, which is highly advantageous in flow photochemistry.

The application of this method to solid phase would also be important to allow it to be compatible with existing automated peptide synthesis systems, but also for forming welldefined peptide sequences on surfaces in a spatially resolved manner, much like the way DNA chips are made." He concluded: "Due to the possibility of activating the charge-transfer complex using light sources with spatial control, this method may find use in the preparation of materials, including in 3D printing technologies."

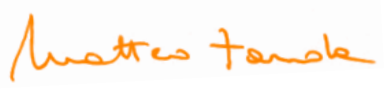

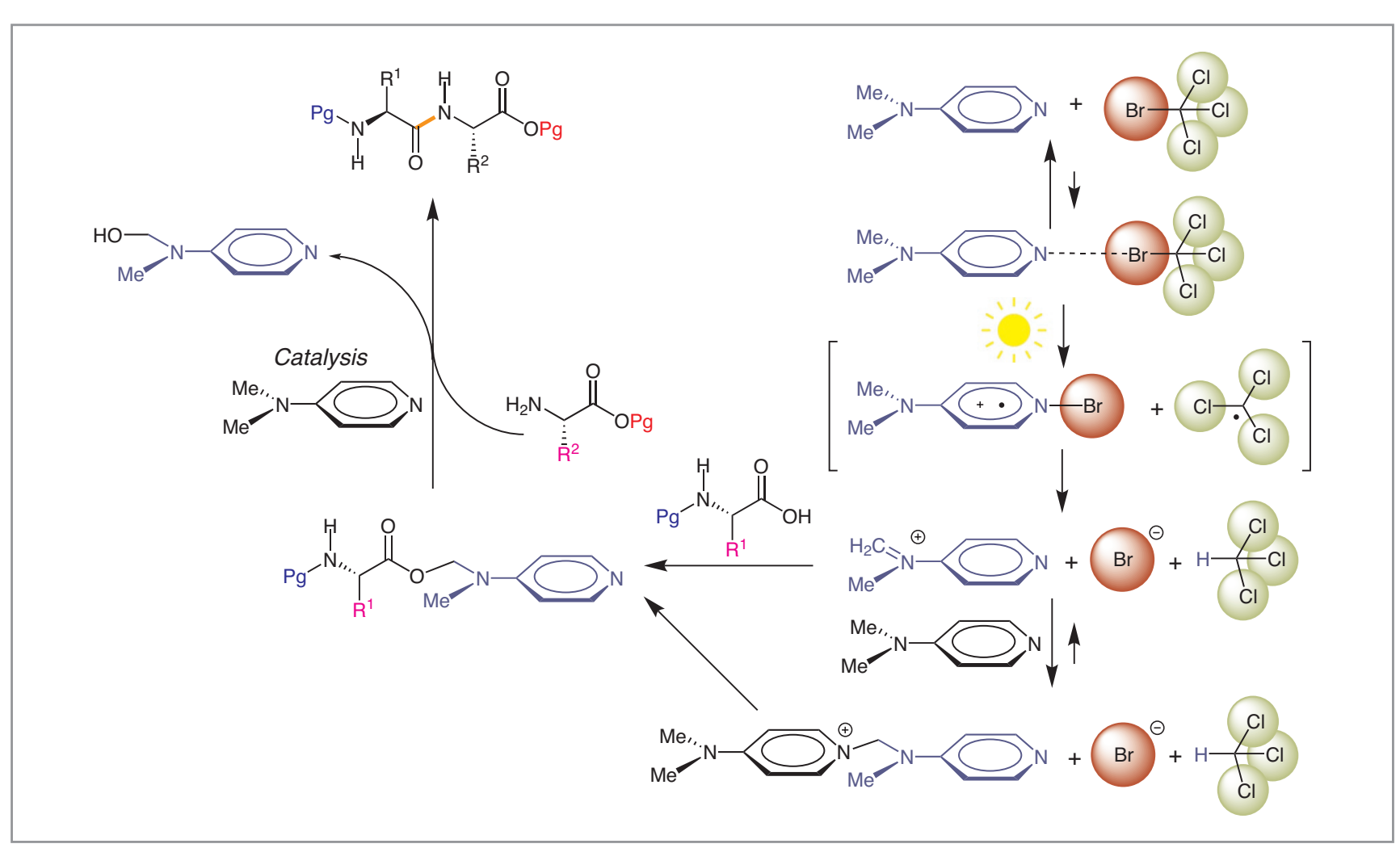

Scheme 2 Proposed mechanism 


\section{REFERENCES}

(1) Peptide Synthesis and Applications; K. J. Jensen, P. T. Shelton, S. L. Pedersen (Eds.); Springer: New York, 2013. (2) M. C. Bryan, P. J. Dunn, D. Entwistle, F. Gallou, S. G. Koenig, J. D. Hayler, M. R. Hickey, S. Hughes, M. E. Kopach, G. Moine, P. Richardson, F. Roschangar, A. Steven, F. J. Weiberth Green Chem. 2018, 20, 5082-5103.

(3) C. K. Prier, D. A. Rankic, D. W. C. MacMillan Chem. Rev. 2013, 113, 5322-5363.

(4) J. W. Beatty, C. R. J. Stephenson Acc. Chem. Res. 2015, 48, 1474-1484.

(5) W. J. Lautenberger, E. N. Jones, J. G. Miller J. Am. Chem. Soc. 1968, 90, 1110-1115.

(6) (a) I. Cohen, A. K. Mishra, G. Parvari, R. Edrei, M. Dantus, Y. Eichen, A. M. Szpilman Chem. Commun. 2017, 53, 1012810131. (b) A. K. Mishra, G. Parvari, I. Cohen, N. Fridman, Y. Eichen, A. M. Szpilman J. Coord. Chem. 2018, 71, 20822089.

(7) D. M. Schultz, T. P. Yoon Science 2014, 343, 1239176.

(8) R. Krishnan, M. J. Frisch, J. A. Pople J. Chem. Phys. 1980, 72, 4244-4245.

(9) H. C. Georg, E. E. Fileti, T. Malaspina J. Mol. Model. 2013, 19, 329-336.

(10) Y. Zhao, D. G. Truhlar Theor. Chem. Acc. 2008, 120, 215-241.

(11) S. Kozuch, J. M. L. Martin J. Chem. Theory Comput. 2013, 9, 1918-1931.

(12) (a) Z. J. Garlets, J. D. Nguyen, C. R. J. Stephenson Isr. J. Chem. 2014, 54, 351-360. (b) N. Hartrampf, A. Saebi, M. Poskus, Z. P. Gates, A. J. Callahan, A. E. Cowfer, S. Hanna, S. Antilla, C. K. Schissel, A. J. Quartararo, X. Ye, A. J. Mijalis, M. D. Simon, A. Loas, S. Liu, C. Jessen, T. E. Nielsen, B. L. Pentelute Science 2020, 368, 980-987.

\section{About the authors}

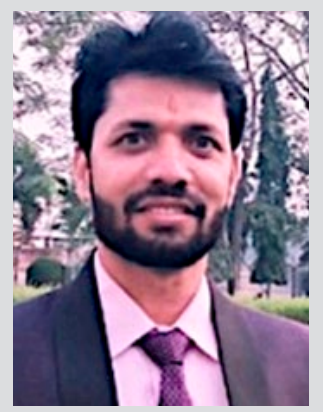

Abhaya Kumar Mishra received his MSc degree in chemistry from St. Andrews College Gorakhpur (India) in 2009, and obtained his PhD from the Indian Institute of Technology Kanpur, India in 2017. He joined the Schulich Faculty of Chemistry, Technion-Israel Institute of Technology (Israel) as a postdoctoral fellow in 2017; there, he was involved in a collaborative project between the Eichen and Szpilman

Dr. A. K. Mishra groups. Currently, he is working at Laboratory of Catalysis
and Organic Synthesis (LCSO), EPFL, Switzerland as a collaborative scientist. His present research interests include synthesis of peptides/proteins and their post synthetic modification using rationally designed hypervalent iodine reagents.

Galit Parvari received her PhD in 2014 from the Schulich Faculty of Chemistry at the Technion-Israel Institute of Technology (Israel). She later continued with postdoctoral studies, and at present is a senior researcher in the group of Professor Yoav Eichen. Her current research interests include the exploration and applications development of inverse freezing materials, and the theoretical study of mechanistic pathways in organic chemistry reactions.

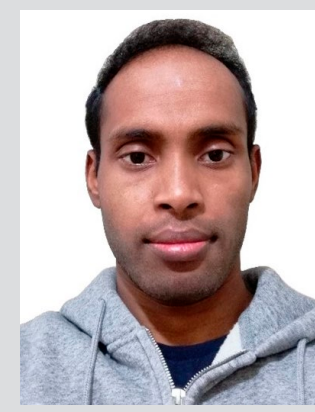

Dr. S. K. Santra
Sourav Kumar Santra received his MSc degree from the Indian Institute of Technology, Guwahati (India) in 2011, and obtained his PhD from IIT Guwahati in 2016. He was a postdoctoral fellow at the Department of Chemical Sciences, Ariel University (Israel), between 2017 and 2020. His current research interests are in the development of new photoredox catalysts and hypervalent iodine mediated umpolung chemistry. 


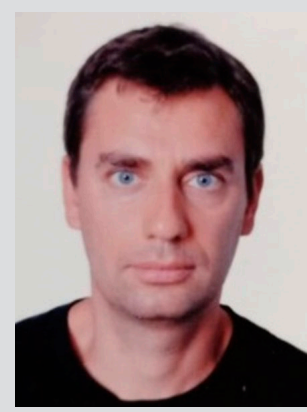

Dr. A. Bazylevich

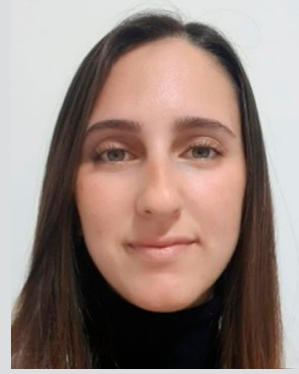

O. Dorfman

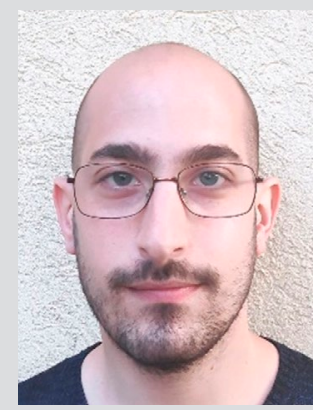

Jonatan Rahamim received his MS degree from Ariel University (Israel) in 2021. He is currently a $\mathrm{PhD}$ researcher at Ariel University. His research interests include the chemistry of chargetransfer complexes and solar-lightassisted reactions.

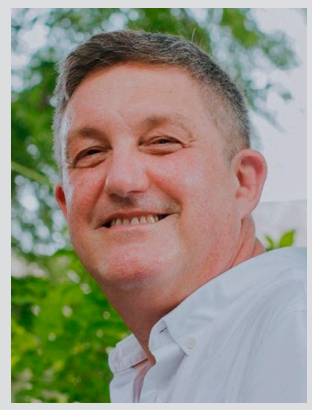

Yoav Eichen received his $\mathrm{PhD}$ from the Hebrew University of Jerusalem (Israel) in 1993 and performed his postdoctoral research at the Université Louis Pasteur, Laboratoire de Chimie Supramoléculaire (France) with Professor J. M. Lehn (19921994). In 1995, he joined the Schulich Faculty of Chemistry at the Technion - Israel Institute of Technology (Israel) where he serves as an associate professor. His current research interests
naterials and the photochemical

Prof. Y. Eichen center on the chemistry of materials and the photochemical processing of materials.

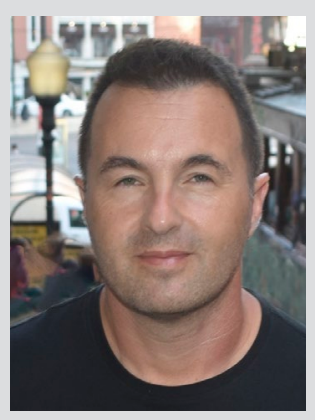

Alex M. Szpilman completed his MSc at the Technical University of Denmark (DTU) with John Nielsen. He earned his PhD in 2003 from the Weizmann Institute of Science (Israel), under the supervision of Professor Mario D. Bachi. Subsequently, he was a Carlsberg Postdoctoral Fellow in the group of Erick M. Carreira at the ETH Zurich (Switzerland). In 2009, Alex started his independent academic career. Currently, Alex

Prof. A. M. Szpliman holds the rank of Associate Professor at Ariel University (Israel) and also serves as the University's Vice Dean for Research. His research group works on new synthetic methods using sunlight, nitroxide catalysis, and hypervalent iodine mediated umpolung of enolates to give enolonium species.

J. Rahamim 


\title{
Asymmetric Three-Component Olefin Dicarbofunctionalization Enabled by Photoredox and Copper Dual Catalysis
}

\author{
Nat. Commun. 2021, 12, 1815
}

Alkenes are among the most privileged and versatile compounds in organic synthesis, because a diverse range of functional groups can be readily introduced across the $C=C \pi$ system by using many well-established and versatile vicinal di-functionalization reactions. In this context, one of the most investigated and fundamental transformations is the intermolecular three-component alkene vicinal di-carbo-functionalization (DCF) reaction, which allows for the installation of two different carbon fragments.

The group of Professors Jia-Rong Chen and Wen-Jing Xiao at Central China Normal University (Wuhan, P. R. of China) has been interested in visible-light photoredox-controlled reactions of iminyl nitrogen radicals. "In recent years, chiral copper catalysis laid the foundations of a new and robust platform for the development of asymmetric radical-mediated alkene DCF reactions, providing a robust and powerful method towards the construction of diverse $\mathrm{C}-\mathrm{C}$ and $\mathrm{C}$-heteroatom bonds, 1,2 " said Professor Chen. "However, despite the broad synthetic applicability of these methods, the intrinsic redox potential window of copper catalysts, which is critical to the generation of radicals, results in certain limitations concerning the range of accessible radical precursors." Recently, Professors Chen and Xiao developed a generally applicable visible-light-driven copper-catalyzed radical cross-coupling reaction of cyanoalkyl carbon radicals, which enables the synthesis of diverse distantly functionalized alkyl nitriles. ${ }^{3}$ In this article, they reported an intermolecular, enantioselective three-component radical vicinal DCF reaction of olefins by merger of radical addition and cross-coupling chemistry, under photoredox and copper dual catalysis (Scheme 1).

"The reaction exhibits a remarkably wide substrate scope, and a range of styrene derivatives with electron-donating (e.g., $\mathrm{Me},{ }^{t} \mathrm{Bu}, \mathrm{Ph}$ ) or electron-withdrawing (e.g., $\mathrm{F}, \mathrm{Cl}, \mathrm{Br}, \mathrm{OAc}$, Bpin) functional groups are well tolerated, furnishing the corresponding products in good yields and stereoselectivity," said Professor Chen, who continued: "This protocol can also be successfully extended to biologically relevant molecules and pharmaceutically derived styrene analogues. For instance, alkenes derived from estrone, febuxostat, and simple amino acids, reacted well to give the desired acylcyanation products with good stereoselectivity." Besides that, the group also demonstrated that the catalytic system could also be success- fully extended to the reaction of cycloketone-derived oxime esters, alkenes, and TMSCN. "A representative set of oxime esters bearing a variety of functional groups, which can be easily prepared in two steps from the relevant ketone precursors, underwent the reaction successfully," said Professor Chen, who continued by explaining that diverse further transformations of the chiral $\beta$-cyano ketones and alkyldinitriles to chiral amides, aliphatic amines and esters were successfully realized, and gram-scale synthesis could be easily achieved.

Professor Chen concluded: "We have developed an intermolecular, highly enantioselective three-component radical vicinal DCF reaction of alkenes, using oxime esters and TMSCN, by exploiting the potential of dual photoredox and copper catalysis. This three-component reaction proceeds under mild conditions, and demonstrates broad substrate scope and high functional group tolerance, providing a general approach to optically active $\beta$-cyano ketones and alkyl-dinitriles."

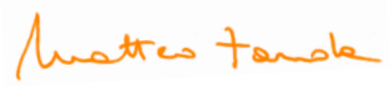

\section{REFERENCES}

(1) F. Wang, P. Chen, G. Liu Acc. Chem. Res. 2018, 51, 20362046.

(2) Z.-L. Li, G.-C. Fang, Q.-S. Gu, X.-Y. Liu Chem. Soc. Rev. 2020, 49, 32-48.

(3) X.-Y. Yu, Q.-Q. Zhao, J. Chen, W.-J. Xiao, J.-R. Chen Acc. Chem. Res. 2020, 53, 1066-1083. 
Cu-catalyzed, three-component radical alkene vicinal dicarbofunctionalization

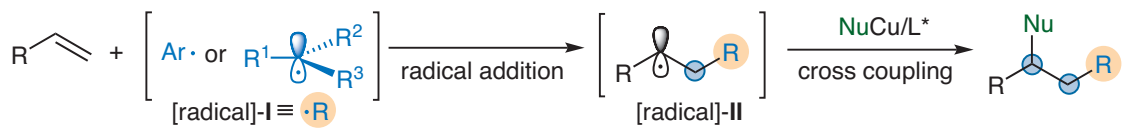

First asymmetric, three-component alkene DCF with oxime esters and TMSCN (this work)

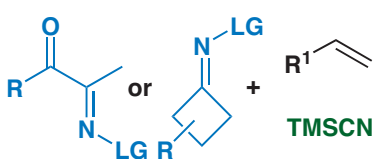

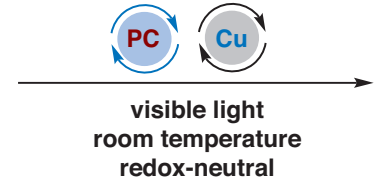<smiles>CCCC(=O)OC(C)C#N</smiles>

- High functional group tolerance

- Broad scope of C-radical precursors

- Excellent chemo- and enantioselectivity
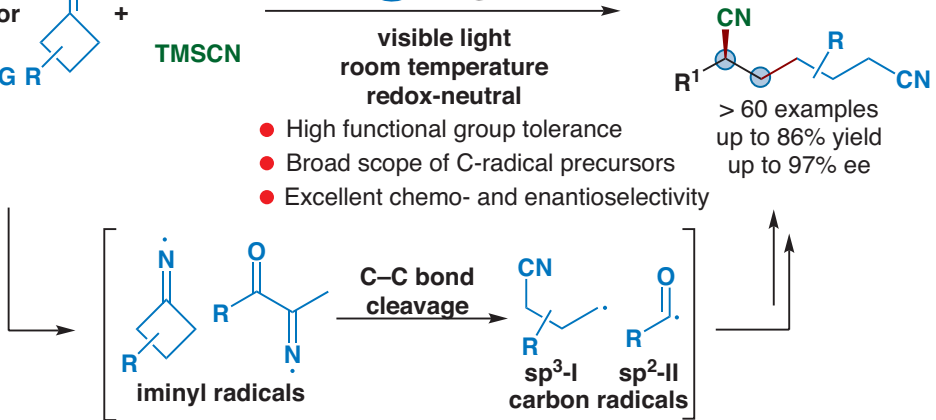

$$
\text { up to } 86 \% \text { yield }
$$
up to $97 \%$ ee<smiles>CC=CC</smiles>

Selected examples
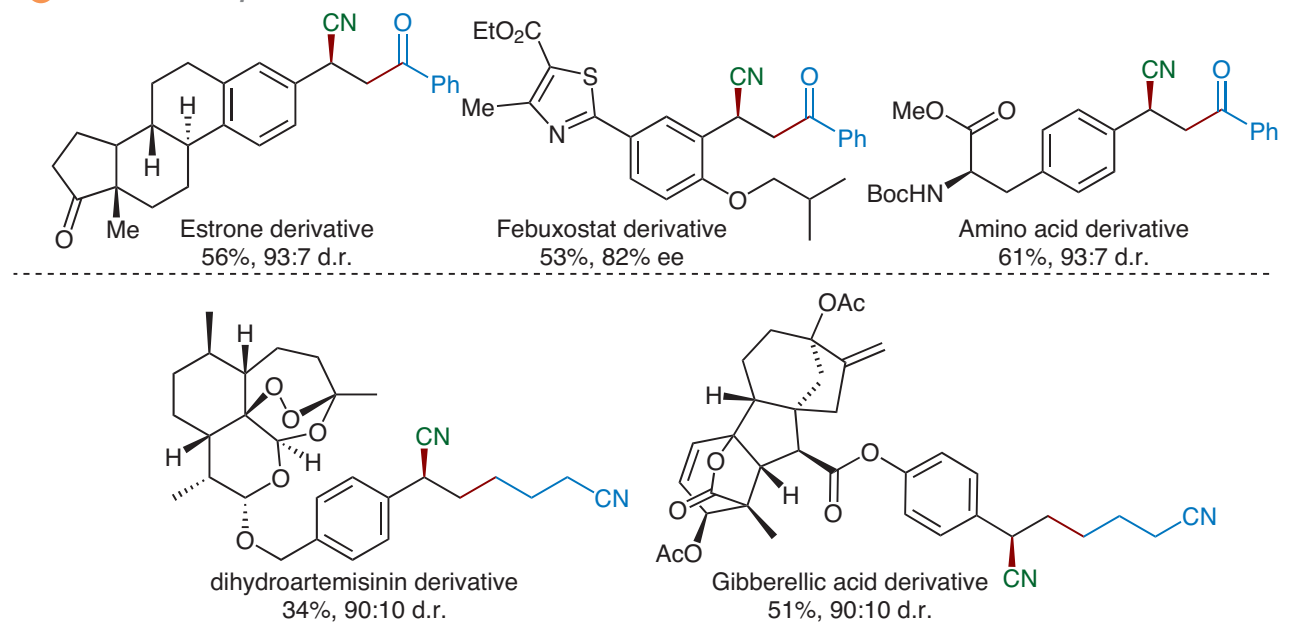

Scheme 1 Catalytic asymmetric, three-component di-carbo-functionalization (DCF) reactions of alkenes with oxime esters and TMSCN: reaction design and selected examples 


\section{About the authors}

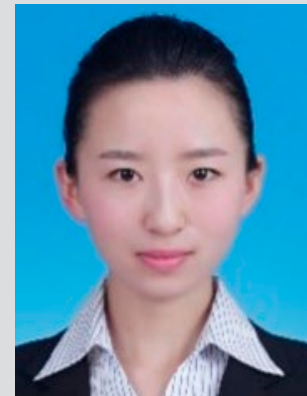

P.-Z. Wang

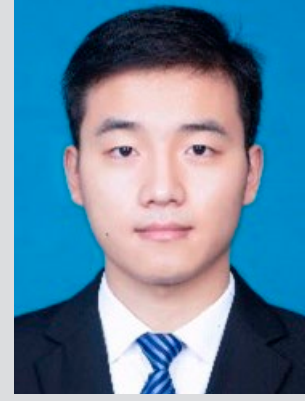

Y. Gao

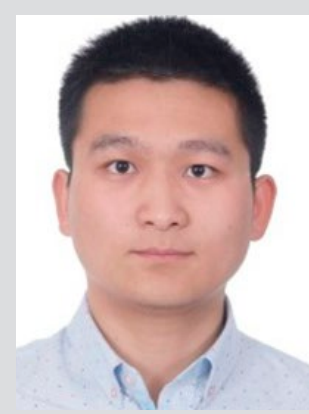

Jun Chen received his B.S. from Hubei Normal University (P. R. of China) in 2015. Then, he began his Ph.D. studies under the supervision of Professors jia-Rong Chen and Wen-Jing Xiao at CCNU (P. R. of China). His research interests focus on photocatalysis and nitrogen radical chemistry.

Peng-Zi Wang received her B.S. from Nanjing Normal University (NNU, P. R. of China) in 2017. Subsequently, she began her Ph.D. studies under the supervision of Professors Jia-Rong Chen and Wen-Jing Xiao at Central China Normal University (CCNU, P. R. of China). Her research interests focus on photocatalysis and nitrogen radical chemistry.

Yuan Gao received his B.S. from Shandong Agricultural University (P. R. of China) in 2018. Subsequently, he began his M.S. studies under the supervision of Professors Jia-Rong Chen and Wen-jing Xiao at CCNU (P. R. of China). His research interests focus on photocatalysis and nitrogen radical chemistry.

nitrogen radical chemistry.

J. Chen

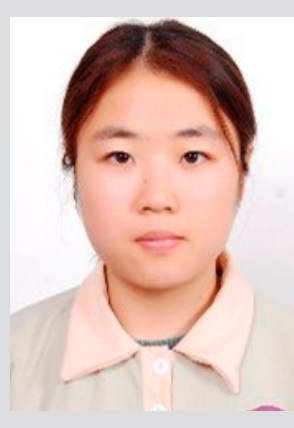

Xiao-Die Huan received her B.S. from Liaocheng University (P. R. of China) in 2020. Subsequently, she began her M.S. studies under the supervision of Professors jia-Rong Chen and Wenjing Xiao at CCNU (P. R. of China). Her research interests focus on photocatalysis and nitrogen radical chemistry.

\section{X.-D. Huan}

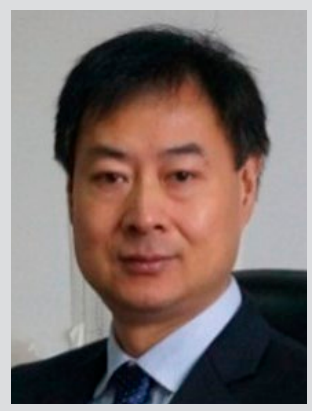

Wen-Jing Xiao received his Ph.D. in 2000 under the direction of Professor Howard Alper at the University of Ottawa (Canada). After postdoctoral studies with Professor David W. C. MacMillan (2001-2002) at the California Institute of Technology (USA) in 2003, Dr. Xiao became a full professor at the College of Chemistry at CCNU (P. R. of China). His research Prof. W.-J. Xiao interests include the development of new synthetic methodologies and the synthesis of biologically active compounds.

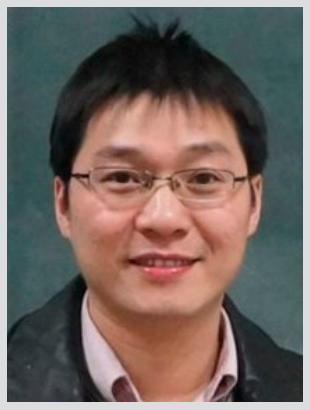

Jia-Rong Chen earned his Ph.D. from CCNU (P. R. of China) under the supervision of Professor Wen-jing Xiao (2009). After holding a position at CCNU (2009-2010), he worked as a Humboldt Postdoctoral Fellow with Professor Carsten Bolm at the RWTH Aachen University (Germany) (20112012). In 2012, he returned to CCNU and began his independent career an associate professor. Chen's research interests include nitrogen radical chemistry, photoredox catalysis, and asymmetric catalysis. 


\title{
Trifluoromethanesulfonyl Azide as a Bifunctional Reagent for Metal-Free Azidotrifluoromethylation of Unactivated Alkenes
}

\author{
Chem. Sci. 2021, 12, 3210-3215
}

Trifluoromethyl-containing molecules have significant importance in medicinal chemistry due to the unique physicochemical and electronic properties of fluorinated substituents (Science 2007, 317, 1881-1886). However, the trifluoromethyl group is entirely xenobiotic - e.g. not found in nature so the only accessible entry to $\mathrm{CF}_{3}$-substituted molecules is chemical synthesis, which renders this area of research a particularly exciting and stimulating challenge for organic chemists. Alkene azido-trifluoromethylation is a straightforward strategy to concomitantly install a trifluoromethyl group and an azide group in a single step across a carbon-carbon double bond. However, the state-of-the-art catalytic methods based on azido-trifluoromethylation are limited to transitionmetal-catalyzed three-component reactions, which generally

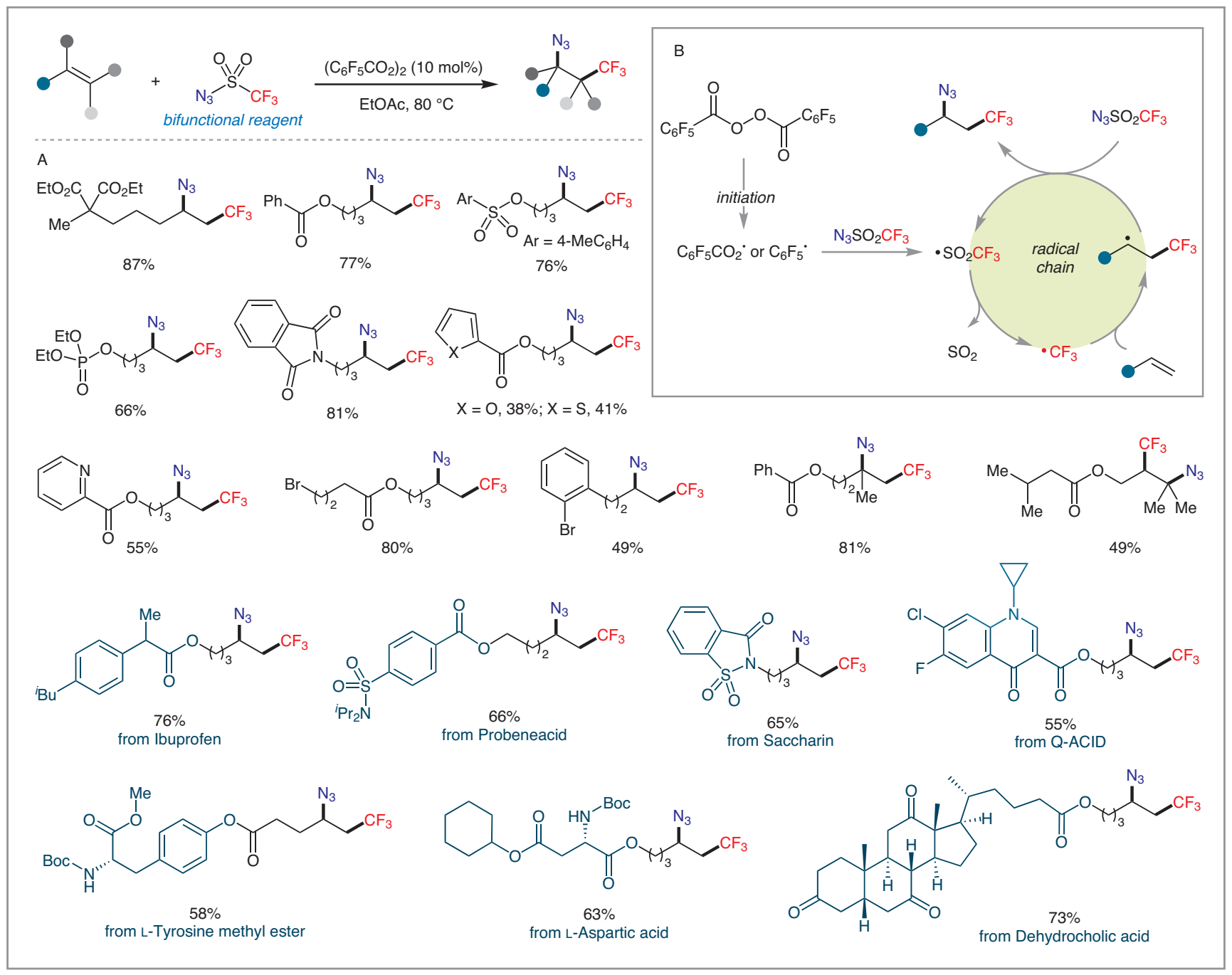

Scheme 1 Trifluoromethanesulfonyl azide as a bifunctional reagent for azido-trifluoromethylation of unactivated alkenes. A: Selected examples. B: Proposed mechanism. 
require the use of expensive $\mathrm{CF}_{3}$ sources (e.g., Togni's reagents, Umemoto's reagent) and a separate azide reagent; moreover, it generally features a low level of mass efficiency. Therefore, the development of more environmentally benign and atomeconomic alternatives is synthetically appealing, besides being conceptually novel.

The group of Professor Wen-Bo Liu at Wuhan University (P. R. of China) was investigating the use of trifluoromethanesulfonyl azide $\left(\mathrm{N}_{3} \mathrm{SO}_{2} \mathrm{CF}_{3}\right)$ as a nitrene precursor in the ironcatalyzed intermolecular allylic $\mathrm{C}-\mathrm{H}$ amination reaction, when a serendipitous discovery, namely a direct azido-trifluoromethylation of the alkene by $\mathrm{N}_{3} \mathrm{SO}_{2} \mathrm{CF}_{3}$, occurred. "After systematic optimization, we finally developed an unprecedented azido-trifluoromethylation reaction of unactivated alkenes employing $\mathrm{N}_{3} \mathrm{SO}_{2} \mathrm{CF}_{3}$ as a bifunctional reagent for the introduction of both $\mathrm{CF}_{3}$ and $\mathrm{N}_{3}$ groups under metal-free conditions (Scheme 1)," said Professor Liu. He continued: "This simple method avoids the use of expensive and low-atomeconomy $\mathrm{CF}_{3}$ precursors, and allows quick access to vicinal trifluoromethyl azides. The substrate scope is substantial, with heterocycles and amino acids being well tolerated." The application of this method was also illustrated by the group through scale-up synthesis, late-stage functionalization of complex bio-important molecules, and derivatization of the products into $\mathrm{CF}_{3}$-containing amines and other privileged heterocycles. Professor Liu observed: "Mechanistic investigations revealed that this reaction probably involves a radical chain process. After being initiated by thermal decomposition of an acyl peroxide and addition of a resulting radical to $\mathrm{N}_{3} \mathrm{SO}_{2} \mathrm{CF}_{3}$, a trifluoromethyl radical is generated and this adds across the alkene double bond providing an alkyl radical, which in turn reacts with $\mathrm{N}_{3} \mathrm{SO}_{2} \mathrm{CF}_{3}$ yielding the azido-trifluoromethylation product along with regeneration of the chain-carrying radical."

Professor Liu concluded: "We believe that this simple strategy provides a new pattern for the difunctionalization of alkenes, which is especially useful for the synthesis of complex pharmaceutical compounds from readily available feedstock chemicals, such as abundant alkenes. Given its atom-economic nature and cost-efficient features, this method could find applications in organic synthesis and medicinal chemistry."

$$
\text { hattes tamb }
$$

\section{About the authors}

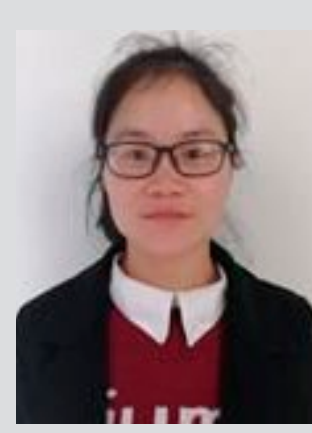

Hong-Gui Huang received her B.S. degree from the College of Chemistry, Hubei Normal University (P. R. of China) in 2015 under the supervision of Prof. Yan-Jun Hu, and M.S. degree from the College of Chemistry, Fuzhou University (P. R. of China) in 2018 under the supervision of Prof. Yi Li. She is now a PhD candidate at the College of Chemistry and Molecular Sciences, Wuhan University (P. R. of China) H.-G. Huang under the supervision of Prof. Wen-Bo Liu. Currently, her research focuses on the development of environmentally benign synthetic methods.

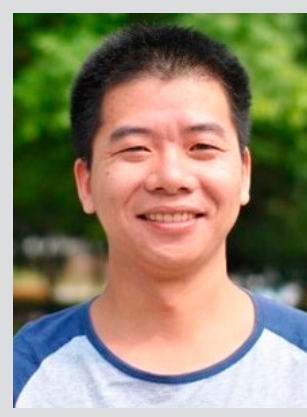

Dr. W. Li

Weishuang Li received his B.S. degree from the College of Chemistry and Life Sciences, China Three Gorges University (P. R. of China) in 2012, his M.S. degree from the College of Chemistry and Chemical Engineering of Lanzhou University (P. R. of China) in 2015, and his Ph.D. from the College of Chemistry and Molecular Sciences of Wuhan University (P. R. of China) in 2019. He is now a postdoctoral researcher at the laboratory of Prof. Wen-Bo Liu. His current research interests include inexpensive metal catalysis and heterocycle synthesis.

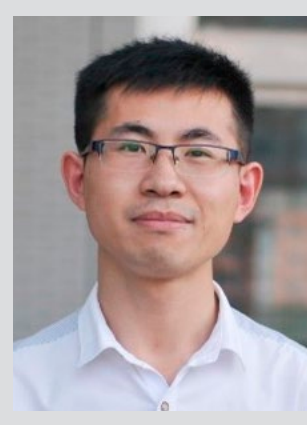

Dr. D. Zhong
Dayou Zhong received his B.S. degree from Pharmacy Faculty of Hubei University of Chinese Medicine (P. R. of China) in 2013, his M.S. degree from the School of Pharmaceutical Sciences of Wuhan University (P. R. of China) in 2015, and his Ph.D. from the College of Chemistry and Molecular Science of Wuhan University (P. R. of China) in 2019. He is now a postdoctoral researcher at the Institute for Advanced Studies of Wuhan University (P. R. of China). His current research includes the design and synthesis of novel chiral ligands and their applications in iron-catalyzed C-H functionalization. 


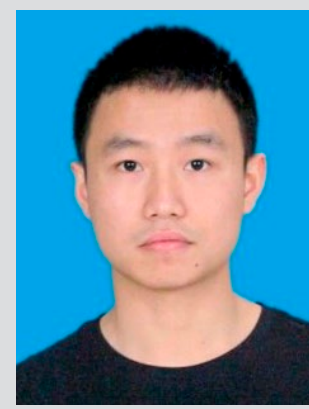

Hu-Chong Wang received his BS degree (2020) from Wuhan University of China (P. R. of China) under the supervision of Prof. Wen-Bo Liu. He is currently a first-year graduate student in the research group of Prof. Shu-Li You at Shanghai Institute of Organic Chemistry (SIOC), Chinese Academy of Sciences.

\section{H.-C. Wang}

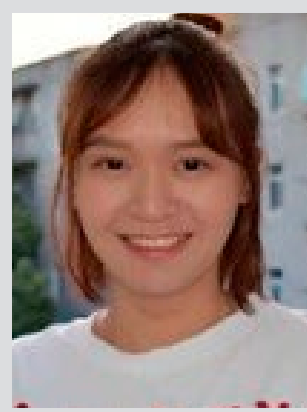

Jing Zhao received her B.S. degree from the College of Chemistry, Central China Normal University (P. R. of China) in 2018, under the supervision of Prof. An-Xin Wu. She is currently pursuing her Master's degree in the group of Prof. Wen-Bo Liu at Wuhan University (P. R. of China). She focuses on the development of new alkene difunctionalization methods.

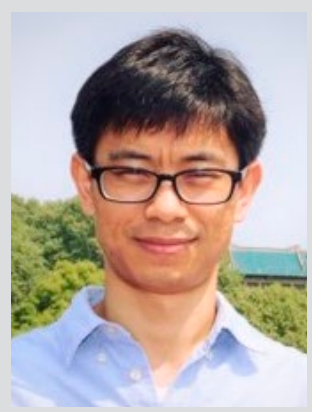

Prof. W.-B. Liu
Wen-Bo Liu was born in China and received his Bachelor's degree in chemistry from Nankai University (P. R. of China) in 2006. He obtained his Ph.D. in organic chemistry (2011) from Shanghai Institute of Organic Chemistry (SIOC, P. R. of China) under the supervision of Prof. Li-Xin Dai and Prof. Shu-Li You. After working as a postdoctoral scholar with Professor Brian M. Stoltz at Caltech (USA), he started his independent research at Wuhan University (P. R. of China) in 2016. His group's research interests include asymmetric catalysis, green synthetic chemistry, and silicon chemistry.

J. Zhao 


\section{Coming soon}

- Literature Coverage

Direct Catalytic Asymmetric Synthesis of $\alpha$-Chiral

Bicyclo[1.1.1]pentanes

Literature Coverage

Sequential C-F Bond Functionalizations of Trifluoroacetamides and Acetates via Spin-Center Shifts

- Literature Coverage

Benzylic C-H Acylation by Cooperative NHC and Photoredox Catalysis

\section{Further highlights}

Synthesis Review: Synthesis of Chiral Amines by C-C Bond Formation with Photoredox Catalysis

(by G. K. Friestad, S. T. J. Cullen)

Synlett Account: Harnessing C-O Bonds in Stereoselective Cross-Coupling and Cross-Electrophile Coupling Reactions (by E. R. Jarvo, A. B. Sanford)

\section{Synfacts Synfact of the Month in category "Peptide} Chemistry": Palladium-Catalyzed Olefination of OxazoleContaining Peptides
Editor

Matteo Zanda

C.N.R. - Istituto di Scienze e Tecnologie Chimiche (SCITEC)

Via Mancinelli, 7, 20131 Milano, Italy

Editorial Assistant: Alison M. Sage, syr

Editorial Office

Senior Director:

Susanne Haak, susanne.haak@thieme.de

- Scientific Editors:

Stefanie Baumann, stefanie.baumann@thieme.de

Selena Boothroyd, selena.boothroyd@thieme.de

Michael Binanzer, michael.binanzer@thieme.de

Giuliana Rubulotta, giuliana.rubulotta@thieme.de

Kathrin Ulbrich, kathrin.ulbrich@thieme.de

- Acquisition Editor:

Juan Zhang, juan.zhang@thieme.com

Senior Production Manager:

Thorsten Schön, thorsten.schoen@thieme.de

Senior Production Editor:

Thomas Loop, thomas.loop@thieme.d

Production Assistant:

Tobias Brenner, Tobias.brenner@thieme.de

Editorial Assistant:

Sabine Heller, sabine.heller@thieme.de

- Marketing Director:

Julia Stötzner, julia.stoetzner@thieme.de

- Postal Address: Chemistry Journals, Editorial Office, Georg Thieme Verlag KG,

Rüdigerstraße 14, 70469 Stuttgart, Germany.

Homepage: www.thieme-chemistry.com

Publication Information

Synform will be published 12 times in 2021 by Georg Thieme Verlag KG, Rüdigerstraße 14, 70469 Stuttgart, Germany, and is an additional online service for Synthesis, Synlett and Synfacts.

\section{Product Names}

Product names which are in fact registered trademarks may not have been specifically designated as such in every case. Thus, in those cases where a product has been referre to by its registered trademark it cannot be concluded that the name used is public

domain. The same applies to labels, names or other signs.

Ordering Information for Synthesis, Synlett and Synfacts

The Americas: Thieme New York, 333 Seventh Avenue, New York, NY 10001, USA.

Via e-mail: customerservice@thieme.com

Via website: www.thieme-chemistry.com

Phone: +1 212760 0888; Fax: +1 2129470108

Order toll-free within the USA: +18007823488

Europe, Africa, Asia, and Australia: Georg Thieme Verlag KG, Rüdigerstraße 14

70469 Stuttgart, Germany.

Via e-mail: customerservice@thieme.de

Via website: www thieme-chemistry.com

Phone: +49711 8931 421; Fax: +497118931410

Current list prices are available through www.thieme-chemistry.com.

Online Licensing Information

The online versions of Synform as well Synthesis, Synlett, Synfacts and SynOpen are available through www.thieme-connect.com/products/ejournals/journals) where it is also possible to register for a free trial account. For information on multi-site licenses and pricing for corporate customers, as well as backfiles, please contact our regional offices:

The Americas: esales@thieme.com, phone: +1 2125844695

Europe, Africa, Asia (ex. India), and Australia: eproducts@thiemede,

phone: +497118

India: eproducts@thieme.in, phone +91 1204556600

Manuscript Submission to Synthesis, Synlett, and SynOpen

Manuscript submissions will be processed exclusively online via

http://mc.manuscriptcentral.com/synthesis, http://mc.manuscriptcentral.com/synlett and http://mc manuscriptcentral.com/synopen, respectively. Please consult the Instructions for Authors before compiling a new manuscript. The current version and the Word template for manuscript preparation are available for download at www.thieme-chemistry.com.

Ownership and Copyright

(c) 2021. Thieme. All rights reserved.

This publication, including all individual contributions and illustrations published therein, is legally protected by copyright for the duration of the copyright period. Any use

exploitation or commercialization outside the narrow limits set by copyright legislation, without the publisher's consent, is illegal and liable to criminal prosecution. This applies in particular to photocopy reproduction, copyright, cyclostyling, mimeographing or duplication of any kind, translating, preparation of microfilms, and electronic data processing and storage (CD-ROM, DVD, USB memory stick, databases, cloud-based service, ebook and other forms of electronic publishing) as well as making it available to the public (e.g., internet, intranet or other wired or wireless data networks), in particular by displaying on stationary or mobile visual display units, monitors, smart phones, tablets or other devices by download (e.g., e-pub, PDF, App) or retrieval in any other form.

Copyright Permission for Users in the USA

Authorization to photocopy items for internal or personal use, or the internal or person use of specific clients, is granted by Georg Thieme Verlag KC Stuttgart · New York for libraries and other users registered with the Copyright Clearance Center (CCC) Transactional Reporting Service; www.copyright.com. For reprint information in the USA, please contact: journals@thieme.com
SYNFORM issue 2021/08 is available from July 20, 2021

at www.thieme-connect.com/ejournals 